\title{
The Etiologic Classification of Nocturia among 133 Thai Patients in a Tertiary Teaching Hospital
}

\author{
Supanat Sirikulchayanonta, Sompol Permpongkosol ${ }^{*}$ \\ Division of Urology, Department of Surgery, Faculty of Medicine, Ramathibodi Hospital, Mahidol University, Bangkok, Thailand \\ Email: "sompolpermpong@gmail.com
}

Received October 2, 2012; revised November 23, 2012; accepted December 6, 2012

\begin{abstract}
Introduction: Nocturia is categorized into many categories. Each category requires different approaches and treatment. We aimed to obtain data regarding nocturia, classified into categories according to its pathogenesis, in Thai patients. Methods: We reviewed 133 medical records and voiding diaries of the patients who attended a urologic clinic in a tertiary teaching hospital during year 2009-2010 with nocturia problems. Those data were analyzed to sort these nocturia patients into the appropriate categories. Results: There were a total of 133 patients, consisting of 94 males (70.1\%) and 39 females $(29.9 \%)$. Overall mean age was $64.74 \pm 25.85$ years. There was no statistically difference between the two genders (Male $65.94 \pm 24.56$ years vs Female $61.87 \pm 28.24$ years, $p=0.10)$. Among these, 71 patients $(53.4 \%)$ had nocturnal polyuria. Almost all patients (132 patients, 99.2\%) met the criteria for diminished global/nocturnal bladder capacity. The younger patients (less than 40 years) were found to have more severe clinical symptoms than the older patients (6 from 8 or $75 \%$ vs 46 from 125 or $36 \%, p=0.032$ ). Seventy patients $(52.6 \%)$ met the criteria of Mixed NP and Diminished. There were 32 patients (24.1\%) found in the group of Global polyuria. Only one patient was classified as isolated nocturnal polyuria and none as isolated global polyuria. Conclusion: Nocturnal polyuria and global polyuria are not uncommon conditions and most of these patients might have concomitant diminished bladder capacity for which investigation or simultaneous treatment may be needed to gain the best treatment result.
\end{abstract}

Keywords: Nocturia; Prevalence; Etiology; Classification; Sleep Disorders

\section{Introduction}

Nocturia, according to International continence society 2002, was defined as the complaint forcing an individual to wake at night one or more times to void [1]. It is one of the most common complaints in urological practice $[2$, $3]$. With overall prevalence $11 \%-33.5 \%$ in various population studies [4-8] and $58.5 \%$ among older adults, [9] patients are affected by worsening health, sleep deprivation, poor quality of life, dissatisfaction with work and even unexpected accidents [5,10-15]. In the past, most patients who presented with nocturia were diagnosed and treated for bladder outlet obstruction (BOO) and overactive bladder $(\mathrm{OAB})$; some of them did not respond to the treatment. Later on, after the pathogenesis of nocturia was better clarified, nocturia was then classified into 4 main categories [1,16,17]: 1) Nocturnal polyuria, 2) Diminished nocturnal and/or global bladder capacity, 3) Global polyuria 4) Mixed nocturnal polyuria and diminished nocturnal and/or global bladder capacity $[1,16]$. However, for individual cases, more than one of these etiologies might be involved [17]. This classification

\footnotetext{
"Corresponding author.
}

helped urologists to precisely diagnose nocturia and delineate it according to its pathogenesis which should lead to more appropriate treatment.

There are some prevalent studies in nocturia in Asian countries using questionnaires but these did not represent data according to the classifications listed above $[4,18$, 19]. At present, in Thailand, as well as in other South East Asian countries, to the best of our knowledge, there has been no specific data regarding nocturia. It seemed that the previous researchers focused on the diseases related to nocturia such as $\mathrm{OAB}$ or $\mathrm{BPH}$ rather than the nocturia per se. This particular study aimed to obtain data regarding nocturia in Thai patients. This may be helpful in making precise diagnosis of nocturia and providing rational treatment as well as minimizing the unnecessary or overtreatment for $\mathrm{BOO}, \mathrm{OAB}$.

\section{Materials and Methods}

We reviewed 133 medical records and voiding diaries of the patients who attended a urologic clinic in the Faculty of Medicine, Ramathibodi Hospital, Mahidol University during the years 2009-2010 with pure nocturia problems regardless the duration of their nocturia. All patients were 
checked as to whether their complaints were true nocturia according to the ICS 2002 definition [1] which was mentioned earlier. The inclusion criteria were that each participant had at least a 3-day valid voiding record. No specific age group was intended to be excluded from our study. Patients who had other significant urologic complaints beside nocturia (e.g. pyuria, gross hematuria, dysuria) or previously known pathology (e.g. stone, recurrent UTI, urothelial carcinoma) were excluded from the study. Then, 24 h-void volume (24 h.V), maximal void volume (MVV), night voids and nocturnal urine volume (NUV) were recorded. Arithmetic means of these data were calculated using the formulae in Table 1. Each nocturia category was determined according to the flowchart in Figure 1. All values are presented as means $+/-$ standard deviation. Independent t-test was used to compare the two groups. Pearson's Chi-square test was used as a test of independence between two groups. All tests were 2 -sided, and $\mathrm{p}$ values $<0.05$ were considered statistically significant. All obtained data were statistically analyzed using IBM $^{\circledR}$ SPSS $^{\circledR}$ statistics version 20.

Table 1. Formula used for categorize the patients.

\begin{tabular}{cc}
\hline Formula & Analysis \\
\hline $\mathrm{Ni}=\mathrm{NUV} / \mathrm{MVV}$ & If $\mathrm{Ni}$ is $>1$, nocturia is due to NUV exceeding \\
& $\mathrm{MVV}$ \\
$\mathrm{NPi}=\mathrm{NUV} / 24 \mathrm{~h} . \mathrm{V}$ & If $\mathrm{NPi}$ is $>25 \%, \begin{array}{c}\text { the diagnosis is nocturnal } \\
\text { polyuria }\end{array}$ \\
$\begin{array}{c}\mathrm{NBCi}=\mathrm{ANV}-\mathrm{PNV} \\
(\mathrm{PNV}=\mathrm{Ni}-1)\end{array}$ & If $\mathrm{NBCi}$ is $>0, \begin{array}{c}\text { nocturia occurs at volumes } \\
<\mathrm{MVV}\end{array}$ \\
\hline
\end{tabular}

$24 \mathrm{~h} . \mathrm{V}=24$ hour urine volume; $\mathrm{ANV}=$ actual number of nightly voids; $\mathrm{MVV}=$ maximum voided volume; $\mathrm{NBCi}=$ nocturnal bladder capacity index; $\mathrm{Ni}=$ nocturnal index; $\mathrm{NPi}=$ nocturnal polyuria index; $\mathrm{NUV}=$ nocturnal urine volume; $\mathrm{PNV}=$ predicted number of nightly voids; Adapted from New aspects of the classification of nocturia and polyuria [27].

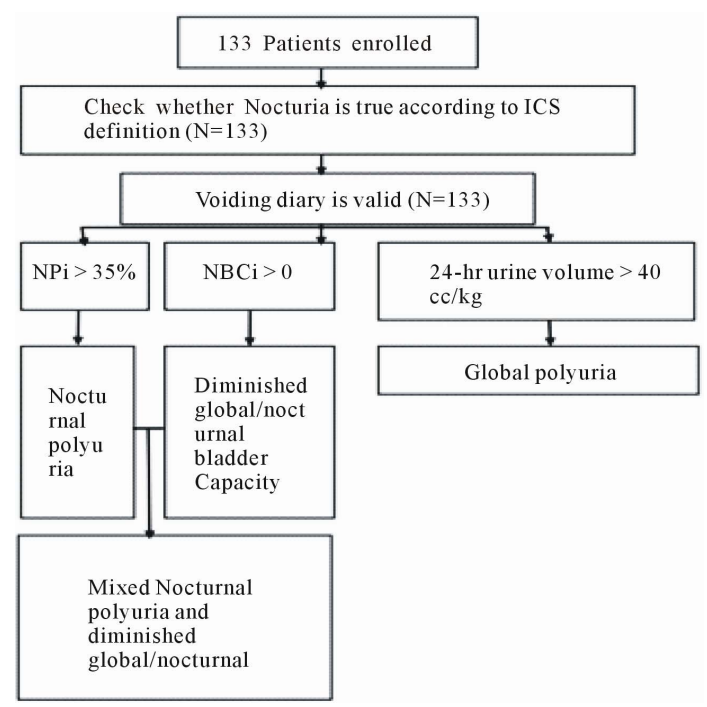

Figure 1. Flow chart showing processes starting from enrollment of cases and algorithm for categorization of cases according to etiologic groups.

\section{Results}

All of the 133 reviewed cases fulfilled the inclusion criteria. There were a total of 133 patients, consisting of 94 males $(70.1 \%)$ and 39 females $(29.9 \%)$. Overall mean age was $64.74 \pm 25.85$ years. There was no statistically significant difference between the two genders. (Male $65.94 \pm 24.56$ years vs. Female $61.87 \pm 28.24$ years, $p=$ $0.10)$. Overall mean weight was $62.86 \pm 20.66 \mathrm{~kg}$. Male weight was significantly greater (Male $64.73 \pm 19.62 \mathrm{~kg}$ vs. Female $58.33 \pm 20.52 \mathrm{~kg}, \mathrm{p}=0.001)$.

Among these, 71 patients $(53.4 \%)$ met the criteria for nocturnal polyuria and there were no statistically significant differences between any age groups or the two genders [Male 54.3\% vs female 51.3\% $(\mathrm{p}=0.754)$ ].

There were 132 patients $(99.2 \%)$ who met the criteria for diminished global/nocturnal bladder capacity. No differences between gender or age groups were noted but the proportion of younger patients (less than 40 years) was found to be significantly greater than the that of older patients among the severe group (6 from 8 or $75 \%$ vs. 46 from 125 or $36 \%, \mathrm{p}=0.032$ ). Seventy patients $(52.6 \%)$ met the criteria of Mixed NP and Diminished NBC and showed no significant differences between sex and age groups. Tables $\mathbf{2}$ and $\mathbf{3}$ show a comparison of the data between groups. Figure 2 represents overlapping between the nocturia categories.

There were 32 patients $(24.1 \%)$ classified in the group for Global polyuria; no significant sex difference was found $[22.3 \%$ vs $28.2 \%(p=0.471)]$. But a significant number of cases were found in the younger group (less than 40 years old) compared to the older group ( 5 from 8 vs 27 from 125, p =0.009). Only one patient was classified as suffering from isolated nocturnal polyuria and none as isolated global polyuria.

\section{Discussion}

Nocturia is one of the most common urologic complaints.

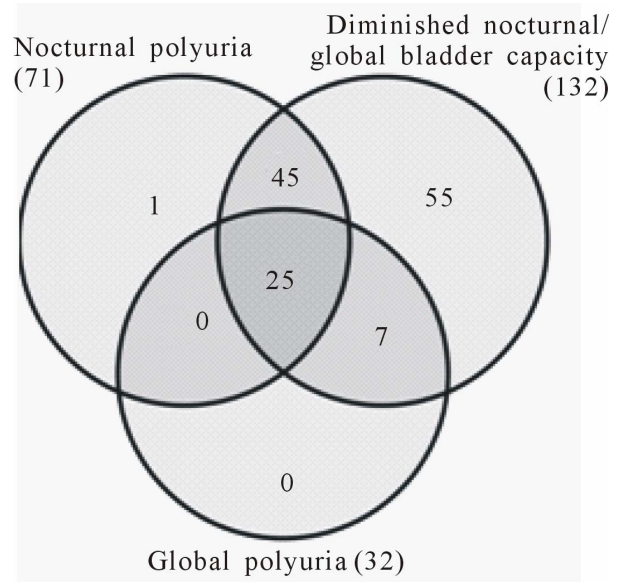

Figure 2. Overlapping between the nocturia categories. 
Table 2. Comparison among each category of nocturia and gender.

\begin{tabular}{cccc}
\hline Categories of Nocturia & Male & Female & Total \\
\hline Nocturnal polyuria & $51(54.3 \%)$ & $20(51.3 \%)$ & $71(53.4 \%, \mathrm{p}=0.75)$ \\
Diminished global/nocturnal bladder capacity & $93(98.9 \%)$ & $39(100 \%)$ & $132(99.2 \%, \mathrm{p}=0.52)$ \\
Severe $(\mathrm{NBCi}>2)$ & $37(61.3 \%)$ & $15(38.5 \%)$ & $52(39.4 \%, \mathrm{p}=0.92)$ \\
Global polyuria & $21(22.3 \%)$ & $11(28.2 \%)$ & $32(24.1 \%, \mathrm{p}=0.47)$ \\
$\begin{array}{c}\text { Mixed Nocturnal polyuria and Diminished } \\
\text { global/nocturnal bladder capacity }\end{array}$ & $50(53.2 \%)$ & $20(51.3 \%)$ & $70(52.6 \%, \mathrm{p}=0.84)$ \\
Total patients & $94(70.7 \%)$ & $39(29.3 \%)$ & $133(100 \%)$ \\
\hline
\end{tabular}

Table 3. Comparison among each category of nocturia and the age group.

\begin{tabular}{ccccccc}
\hline Categories of Nocturia & \multicolumn{5}{c}{ Age group } \\
\cline { 2 - 6 } & $\mathbf{4}$ & $\mathbf{4 0 - 5 0}$ & $\mathbf{5 1 - 6 0}$ & $\mathbf{6 1 - 7 0}$ & $\mathbf{7 1 - 8 0}$ & $>\mathbf{8 0}$ \\
\hline Nocturnal polyuria (71) & $6(75 \%)$ & $4(50 \%)$ & $17(52 \%)$ & $14(45.2 \%)$ & $23(59 \%)$ & $7(50 \%)$ \\
Diminished global/ nocturnal bladder capacity (132) & $8(100 \%)$ & $8(100 \%)$ & $33(100 \%)$ & $31(100 \%)$ & $39(100 \%)$ & $13(92.8 \%)$ \\
Severe (NBCi $>$ 2) (52) & $6(75 \%)$ & $1(12.5 \%)$ & $15(45.5 \%)$ & $11(35.5 \%)$ & $13(33.3 \%)$ & $6(42.9 \%)$ \\
Global polyuria (32) & $5(62.5 \%)$ & $0(0 \%)$ & $10(30.3 \%)$ & $3(9.7 \%)$ & $13(33.3 \%)$ & $1(7.2 \%)$ \\
$\begin{array}{c}\text { Mixed Nocturnal polyuria and Diminished } \\
\text { global/nocturnal bladder capacity (70) }\end{array}$ & $6(75 \%)$ & $4(50 \%)$ & $17(51.5 \%)$ & $14(45.2 \%)$ & $23(59 \%)$ & $6(42.9 \%)$ \\
Total patients (133) & 8 & 8 & 33 & 31 & 39 & 14 \\
\hline
\end{tabular}

It leads to many adverse sequelae including daytime fatigue, attention deficit, emotional disorder, memory problems, etc. [4-9]. According to many studies, there is greater prevalence of nocturia in elderly patients [20-23]. That is consistent with our study; only $12 \%$ of the nocturia patients in this study were less than 50 years of age. Most nocturia patients $(99.2 \%)$ had diminished global/nocturnal bladder capacity. This indicates nocturnal urine volume that exceeds maximal function capacity of the bladder. It may represent some bladder pathology including bladder outlet obstruction, stones, tumors, $\mathrm{OAB}$, etc. The urologist should keep in mind when any nocturia treatment is given and the condition is not improved, further investigation should be considered [1]. Also, from our study, it may be assumed that treatment of nocturnal polyuria by using only antidiuretics may not be adequate because most of these patients also had concomitant diminished global/nocturnal bladder capacity for which simultaneous treatment of the latter may be needed. On the other hand, nocturia patients for whom bladder outlet obstruction or OAB treatment is initiated may not be fully improved because of occult nocturnal polyuria.

Nocturia is a condition thought to be due to the impairment of the ADH secretion circadian pattern during sleep. Elderly plasma ADH decrease during sleep [24] leads us to hypothesize that nocturnal polyuria is commonly found in the elderly. Since our study did not show any difference among age groups this might imply that there might be other factors besides nocturnal ADH secretion impairment that play a role in nocturnal polyuria pathogenesis.

In 1998, Weiss et al. studied 200 nocturia patients and found $7 \%$ were categorized as isolated nocturnal polyuria whereas our study found only $0.75 \%$. They also reported $36 \%$ of those patients were categorized as Mixed Nocturnal polyuria and diminished global/nocturnal bladder capacity while this category amounted to $52.6 \%$ in our present study [25]. The discrepancies might be due to the differences in inclusion criteria of nocturia. Most researchers choose to define nocturia in their study as 2 or more nocturnal voids. In view of evidence that most people with less than 2 voids nightly generally experience only minimal bother from the condition [17], but we decided to use a single nocturnal void as our nocturia definition because we believe these patients certainly face the problem of nocturia, otherwise, they would not come to see a urologist. Study methodology [26], and probably race and socioeconomic factors may also have contributed to the different results.

Moreover, focusing on the patients who had $\mathrm{NBCi}>2$, which indicates severe diminished global/nocturnal bladder capacity [16], there were $39.4 \%$. And a more significant proportion was shown in younger patients (less 
than 40 years old). These data might suggest that urologists should treat conditions that may cause diminished global/nocturnal bladder capacity in young patients prior to treating for existing nocturnal polyuria, because it could be the primary component of their nocturia.

Global polyuria is considered when patient's urine output exceeds $40-\mathrm{ml} / \mathrm{kg}$ bodyweight during a 24-hour period, which is mostly due to non-urologic condition. Medical workup needs to be done for diagnosis and medical referral is necessary [27]. There were $24.1 \%$ of our patients who met such criteria and this was comparable to Weiss' study which found $23 \%$ [25].

None of patients who met the criteria of global polyuria had isolated polyuria. This might indicate that only medical referral is inadequate in the treatment of polyuria because these patients always have concomitant urologic conditions. Data from the present study might not represent the prevalence of nocturia in the general population since it was obtained from cases who presented to our clinic with problems of nocturia, which more or less affected their quality of life. From Chen's study, only $13 \%$ of nocturia patients come to see a physician [28]. There could be many more patients whose qualities of life were not disturbed and so were not included.

Collecting data from overall population would be significantly beneficial to urologists, in terms of both the statistical and clinical aspects. But it is difficult to practically achieve. However, the data from the present study might represent patients who should receive treatment and we may be able to use these data to make presumptive diagnoses, suggest guidelines for investigations and provide appropriate treatment.

For our future project, we intend to conduct a prospective multicenter study to find reliable data on the prevalence of each classification of nocturia in Thailand. We believe that the reliable prevalence of each category of nocturia should have major impact upon the change of the nocturia treatment paradigm and lead to minimize unnecessary treatment.

\section{Conclusion}

Nocturia is classified into many categories according to its pathogenesis. Each category has different approaches and treatment. Among them, nocturnal polyuria and global polyuria are not uncommon conditions, and most of these patients might have concomitant diminished bladder capacity, for which investigation or simultaneous treatment may be needed to gain the best treatment result.

\section{REFERENCES}

[1] P. Abrams, C. Chapple, et al., "Evaluation and Treatment of Lower Urinary Tract Symptoms in Older Men," The Journal of Urology, Vol. 181, No. 4, 2009, pp. 1779-1787. doi:10.1016/j.juro.2008.11.127

[2] R. Asplund and H. Aberg, "Diurnal Variation in the Levels of Antidiuretic Hormone in the Elderly," Journal of Internal Medicine, Vol. 229, No. 2, 1991, pp. 131-134. doi:10.1111/j.1365-2796.1991.tb00320.x

[3] M. H. Blanker, A. M. Bohnen, et al., "Normal Voiding Patterns and Determinants of Increased Diurnal and Nocturnal Voiding Frequency in Elderly Men," The Journal of Urology, Vol. 164, No. 4, 2000, pp. 1201-1205. doi:10.1016/S0022-5347(05)67141-8

[4] K. L. Burgio, T. M. Johnson II, et al., "Prevalence and Correlates of Nocturia in Community-Dwelling Older Adults," Journal of the American Geriatrics Society, Vol. 58 , No. 5, 2010, pp. 861-866. doi:10.1111/j.1532-5415.2010.02822.x

[5] F. Y. Chen, Y. T. Dai, et al., "Perception of Nocturia and Medical Consulting Behavior among Community-Dwelling Women," International Urogynecology Journal and Pelvic Floor Dysfunction, Vol. 18, No. 4, 2007, pp. 431436. doi:10.1007/s00192-006-0167-X

[6] M. S. Choo, J. H. Ku, et al., "Prevalence of Nocturia in a Korean Population Aged 40 to 89 Years," Neurourology and Urodynamics, Vol. 27, No. 1, 2008, pp. 60-64. doi: $10.1002 /$ nau. 20458

[7] C. G. Chute, L. A. Panser, et al., "The Prevalence of Prostatism: A Population-Based Survey of Urinary Symptoms," The Journal of Urology, Vol. 150, No. 1, 1993, pp. 85-89.

[8] K. S. Coyne, Z. Zhou, et al., "The Prevalence of Nocturia and Its Effect on Health-Related Quality of Life and Sleep in a Community Sample in the USA," BJU International, Vol. 92, No. 9, 2003, pp. 948-954. doi:10.1111/j.1464-410X.2003.04527.x

[9] C. E. DuBeau, S. V. Yalla, et al., "Implications of the Most Bothersome Prostatism Symptom for Clinical Care and Outcomes Research," Journal of the American Geriatrics Society, Vol. 43, No. 9, 1995, pp. 985-992.

[10] D. J. Foley, M. V. Vitiello, et al., "Frequent Napping Is Associated with Excessive Daytime Sleepiness, Depression, Pain, and Nocturia in Older Adults: Findings from the National Sleep Foundation '2003 Sleep in America' Poll," The American Journal of Geriatric Psychiatry: Official Journal of the American Association for Geriatric Psychiatry, Vol. 15, No. 4, 2007, pp. 344-350.

[11] D. M. Gulur, A. M. Mevcha, et al., "Nocturia as a Manifestation of Systemic Disease," BJU International, Vol. 107, No. 5, 2011, pp. 702-713. doi:10.1111/j.1464-410X.2010.09763.x

[12] C. H. Hsieh, H. Y. Chen, et al., "Prevalence of Nocturia in Taiwanese Women Aged 20 - 59 Years," Taiwanese Journal of Obstetrics \& Gynecology, Vol. 46, No. 1, 2007, pp. 50-53. doi:10.1016/S1028-4559(08)60107-2

[13] U. G. Malmsten, I. Milsom, et al., "Urinary Incontinence and Lower Urinary Tract Symptoms: An Epidemiological Study of Men Aged 45 to 99 Years," The Journal of Urology, Vol. 158, No. 5, 1997, pp. 1733-1737. doi:10.1016/S0022-5347(01)64113-2

[14] A. D. Markland, C. P. Vaughan, et al., "Prevalence of nocturia in United States Men: Results from the National 
Health and Nutrition Examination Survey," The Journal of Urology, Vol. 185, No. 3, 2011, pp. 998-1002. doi:10.1016/i.juro.2010.10.083

[15] H. A. Middelkoop, D. A. Smilde-van den Doel, et al., "Subjective Sleep Characteristics of 1485 Males and Females Aged 50 - 93: Effects of Sex and Age, and Factors Related to Self-Evaluated Quality of Sleep," The Journals of Gerontology. Series A, Biological Sciences and Medical Sciences, Vol. 51, No. 3, 1996, pp. M108-M115. doi:10.1093/gerona/51A.3.M108

[16] J. K. Parsons, J. Mougey, et al., "Lower Urinary Tract Symptoms Increase the Risk of Falls in Older Men," BJU International, Vol. 104, No. 1, 2009, pp. 63-68.\} doi:10.1111/j.1464-410X.2008.08317.x

[17] K. T. C. H. Hsieh, C. S. Hsu, S. T. Chang and M. C. Lee, "Nocturia among Women Aged 60 or Older in Taiwan," Australian and New Zealand Journal of Obstetrics and Gynaecology, Vol. 48, No. 3, 2008, pp. 312-316. doi:10.1111/j.1479-828X.2008.00870.x

[18] S. Hunskaar, "Epidemiology of Nocturia," BJU International, Vol. 96, Supplement 1, 2005, pp. 4-7. doi:10.1111/j.1464-410X.2005.05650.x

[19] V. Kupelian, R. C. Rosen, et al., "Association of Urological Symptoms and Chronic Illness in Men and Women: Contributions of Symptom Severity and DurationResults from the BACH Survey," The Journal of Urology Vol. 181, No. 2, 2009, pp. 694-700. doi:10.1016/j.juro.2008.10.039

[20] G. Schatzl, C. Temml, et al., "Cross-Sectional Study of Nocturia in Both Sexes: Analysis of a Voluntary Health Screening Project," Urology, Vol. 56, No. 1, 2000, pp. 71-75. doi:10.1016/S0090-4295(00)00603-8

[21] L. V. Swithinbank, S. T. Brookes, et al., "The Natural History of Urinary Symptoms during Adolescence," British Journal of Urology, Vol. 81 Supplement 3, 1998, pp.
90-93. doi:10.1046/j.1464-410x.1998.00016.x

[22] K. A. Tikkinen, A. Auvinen, et al., "A systematic Evaluation of Factors Associated with Nocturia-The Population-Based FINNO Study," American Journal of Epidemiology Vol. 170, No. 3, 2009, pp. 361-368. doi:10.1093/aje/kwp133

[23] L. van Dijk, D. G. Kooij, et al., "Nocturia in the Dutch Adult Population," BJU International, Vol. 90, No. 7, 2002, pp. 644-648. doi:10.1046/j.1464-410X.2002.03011.x

[24] P. van Kerrebroeck, P. Abrams, et al., "The Standardisation of Terminology in Nocturia: Report from the Standardisation Sub-Committee of the International Continence Society," Neurourology and Urodynamics, Vol. 21, No. 2, 2002, pp. 179-183. doi:10.1002/nau.10053

[25] J. P. Weiss, J. G. Blaivas, et al., "Nocturia in Adults: Etiology and Classification," Neurourology and Urodynamics, Vol. 17, No. 5, 1998, pp. 467-472. doi:10.1002/(SICI)1520-6777(1998)17:5<467::AID-NAU 2>3.0.CO;2-B

[26] J. P. Weiss, A. J. Wein, et al., "Nocturia: New Directions," Neurourology and Urodynamics, Vol. 30, No. 5, 2011, pp. 700-703. doi:10.1002/nau.21125

[27] J. P. Weiss, A. C. Weinberg, et al., "New Aspects of the Classification of Nocturia," Current Urology Reports, Vol. 9, No. 5, 2008, pp. 362-367. doi:10.1007/s11934-008-0063-7

[28] K. Yoshimura, N. Terada, et al., "Prevalence of and Risk Factors for Nocturia: Analysis of a Health Screening Program," International Journal of Urology: Official Journal of the Japanese Urological Association, Vol. 11, No. 5, 2004, pp. 282-287. doi:10.1111/j.1442-2042.2004.00791.x 